\title{
PFOS mediates immunomodulation in an avian cell line that can be mitigated via a virus infection
}

\author{
Jose M. Castaño-Ortiz ${ }^{1,2}$, Veerle L. B. Jaspers ${ }^{1}$ and Courtney A. Waugh ${ }^{1 *}$ (D)
}

\begin{abstract}
Background: Per- and polyfluoroalkyl substances (PFASs) are environmentally persistent and bioaccumulative chemicals. Immunomodulation is among the most concerning of toxic effects linked with PFAS exposure in mammalian models. However, no studies had yet shown this to be true in birds. Thus, we designed and conducted the first study to determine if PFASs could cause immunomodulation in birds. Secondly, we wanted to determine the effects on an avian host when exposed not only to immunomodulating chemicals, but also to a viral challenge. The aim, to determine if PFAS mediated immunmodulation functionally affects a pathogen challenge for a host. As innate immune system signalling pathways initiate crucial responses against a pathogen challenge, and are lesser studied than their adaptive counterparts, we focused on these pathways. To provide the first information on this, an in vitro experiment was designed and performed using chicken embryo fibroblasts exposed to perfluorooctane sulfonate (PFOS) (22 ppm) and immune markers characterised before and after being infected with gallid herpesvirus-2 (GaHV-2).

Results: The expression of two pro-inflammatory cytokines, namely interleukin 8 (IL-8) and tumor necrosis factor alpha (TNF-a), the nuclear factor 'kappa-light-chain-enhancer' of activated B-cells (NF-kB), and the anti-inflammatory cytokine interleukin 4 (IL-4) were investigated in various scenarios. These results showed that exposure to PFOS decreased immune gene expression in chicken fibroblasts from $36 \mathrm{~h}$ post-exposure. Next, it was shown that this decrease could be mitigated by infection with gallid herpesvirus-2, which increased gene expression back to the baseline/control levels.

Conclusions: Not only is this the first study to provide the expected evidence that PFOS has immunomodulatory potential in birds, it also provides unexpected data that virus infections can mitigate this negative effect. Thereby, further research, including in vivo and in situ studies, on the impact of PFOS on host-virus interactions is now warranted, as it has been overlooked and might contribute to our understanding of recent disease outbreaks in wildlife. The mechanisms by which gallid herpesvirus mitigates immunomodulation were beyond the scope of this study, but are now of interest for future study.
\end{abstract}

Keywords: PFASs, Immunotoxicity, Birds, PFOS, Gallid herpesvirus-2, Cytokines, qPCR

\footnotetext{
* Correspondence: courtney.waugh@ntnu.no

${ }^{1}$ Department of Biology, Norwegian University of Science and Technology

(NTNU), Høgskoleringen 5, 7491 Trondheim, Norway

Full list of author information is available at the end of the article
}

(c) The Author(s). 2019 Open Access This article is distributed under the terms of the Creative Commons Attribution 4.0 International License (http://creativecommons.org/licenses/by/4.0/), which permits unrestricted use, distribution, and reproduction in any medium, provided you give appropriate credit to the original author(s) and the source, provide a link to the Creative Commons license, and indicate if changes were made. The Creative Commons Public Domain Dedication waiver (http://creativecommons.org/publicdomain/zero/1.0/) applies to the data made available in this article, unless otherwise stated. 


\section{Background}

Per- and polyfluoroalkyl substances are highly fluorinated aliphatic chemicals with unique physicochemical properties, which have prompted their use in a wide variety of industrial and commercial applications including surfactants, paints, repellent coatings, fire-fighting foams and ski wax [1-3]. The environmental persistence of PFASs, and their low elimination rates, leads to bioaccumulation in organisms and widespread occurrence across ecosystems $[3,4]$. Immunomodulation is one of the most well-known biological effects associated with PFAS exposure in mammals [5]. Yet, there has been limited epidemiological studies to assess a link between PFAS mediated immunomodulation and disease outbreaks in humans [6] and wildlife [7]. Experimental studies, with traditional models, have already demonstrated a range of immune effects, including atrophy of lymphoid organs, and impairment of lymphocyte proliferation or antibody production $[8,9]$. The immunomodulation of PFASs in non-mammalian models, such as birds, however, remains understudied, and research to date has focused on adaptive immunity only. For example, Peden-Adams et al. [10] found a decreased response to the phytohemagglutinin (PHA) skin test in white leghorn chickens (Gallus Gallus domesticus) following in ovo exposure to perfluorooctane sulfonate (PFOS) (1-5 $\mu \mathrm{g} / \mathrm{g}$ egg wt). Smits and Nain [11] demonstrated a downregulation of the T-cell dependent antibody response (TDAR) in Japanese quails (Coturnix japonica) exposed to perfluorooctanoic acid (PFOA) via drinking water $(0.1-10 \mu \mathrm{g} / \mathrm{ml})$ for eight weeks. However, no relationship was established between PFASs and immunoglobulin levels in plasma of wild white-tailed eagle (Haliaeetus albicilla) nestlings from northern Norway [12]. A knowledge gap thereby exists in the understanding of potential effects of PFASs on innate immunity in birds [13].

Innate immunity comprises physical barriers, such as skin and mucosal linings, and a variety of biochemical and cellular responses to infection, including inflammatory responses, and represents the first line of defence against invading pathogens [14]; changes in innate immune function can therefore be hypothesised to impact disease resistance and persistence [15]. Early antiviral responses, for example, are initiated with the activation of pattern recognition receptors (PRRs), by pathogen associated molecular patterns (PAMPs), that eventually trigger the synthesis of various cytokines [14]. For example, gallid herpesvirus-2 (GaHV-2) can interact with toll-like receptor 3 (TLR3) and upregulate the release of interleukin (IL)-8, which is a major pro-inflammatory chemokine [16, 17]. TLR3 ligands induce the activation of NF- $\mathrm{KB}$ signalling using the MyD88-independent pathway [18]. It is known from mammalian models that innate signalling cascades can be negatively regulated by PFAS exposure, leading to attenuation of NF- $\mathrm{BB}$ activity and associated pro-inflammatory mediators [13]. Research into the mechanistic aspects of immunomodulation has demonstrated that peroxisome proliferatoractivated receptor (PPAR $\alpha$ ) agonists, like PFASs, may interfere with the propagation of infectious signals [19]. Alternatively, PPAR $\alpha$-independent mechanisms may account for PFAS immunomodulation as well [20].

Perfluorooctane sulfonate (PFOS) is the most commonly occurring PFAS in biota, including birds, followed by long-chain perfluoroalkyl carboxylates (PFCAs). In addition, pharmacokinetic properties and immunotoxic effects are the most intensively studied for PFOS, together with perfluorooctanoic acid (PFOA) [21]. Thereby the present study aimed to characterize the effect of PFOS on the antiviral response to infection in birds by using an in vitro model infected with gallid herpesvirus2 (GaHV-2). GaHV-2, also referred to as Marek's disease virus (MDV), is an oncogenic $\alpha$-herpesvirus that causes Marek's disease, which is a contagious lymphoproliferative disease in domestic fowl [22]. Chickens are primarily exposed to GaHV-2 through inhalation of air-borne viral particles, that then infect antigen-presenting cells, or intermediate cells, from the lung epithelium [23]. GaHV-2 represents a worldwide problem for the poultry industry, and it provides a model of interest for the understanding of virus induced tumorigenesis [22]. Thereby, we designed a targeted study to address the effect of PFOS on the expression of important innate immune signalling components following GaHV-2 infection. Specifically, changes in the relative expression of four immune associated genes were investigated, namely the nuclear factor 'kappa-light-chain-enhancer' of activated B-cells (NF-kB), tumor necrosis factor alpha (TNF- $\alpha$ ), interleukin 8 (IL-8) and interleukin 4 (IL-4). An avian cell line (chicken (Gallus gallus) embryo fibroblasts (CEFs)) were selected as the in vitro model system, due to the global relevance of avian diseases [24] and widespread use of birds in ecotoxicology [25]. In addition, further research, especially in birds, is needed to elucidate potential effects of PFASs on innate immune signalling pathways, and on host-virus interactions [13]. Therefore, we evaluated the expression of NF- $\mathrm{kB}$, TNF- $\alpha$, IL-8 and IL-4 in CEFs following: (i) infection with GaHV2, (ii) exposure to PFOS, and (iii) combination of both (exposure to PFOS followed by infection with GaHV-2).

This is of importance because an efficient response to infection in the early recognition of GaHV-2 has been shown to be crucial to the determination of either a positive or negative outcome [26]. Previous studies demonstrated that herpesviruses triggered innate immune signalling cascades when binding to PRRs, including TLRs, retinoic acid-inducible gene I-like receptors 
(RLRs), and cytosolic DNA sensors [27]. This led to the activation of key transcription factors such as NF- $\mathrm{kB}$, secretion of type I interferons (IFNs) and a set of proinflammatory cytokines in chicken tissues and tissue culture cells [27-30]. Any deregulation of these pathways generally led to a more severe outcome in relation to disease severity. We thereby hypothesise that 1) PFOS has the ability to deregulate important innate immune signalling pathways in birds; and 2) that exposure to PFOS can worsen the outcome of an infection in a host.

\section{Methods}

\section{Cultivation of fibroblasts, GaHV-2, and combined exposure to PFOS and GaHV-2}

Chicken embryo fibroblasts (CEFs) were purchased from the American Type Culture Collection (ATCC CRL12203 ${ }^{\text {tix }}$ Gallus gallus embryo) and were cultivated in Dulbeccos modified Eagle's $\mathrm{s}$ medium (DMEM, Sigma, Oslo, Norway), 5\% foetal calf serum (FCS, Sigma, Oslo, Norway), $50 \mathrm{mg} / \mathrm{mL}$ Gentamycin (Sigma, Oslo, Norway), 100 units $/ \mathrm{mL}$ Penicillin and $100 \mu \mathrm{g} / \mathrm{mL}$ Streptomycin. Gallid herpesvirus-2 (GaHV-2) was purchased from LGC Standards GmbH (ATCC ${ }^{\circ}$ VR-2175 ${ }^{\mathrm{mm}}$ ) . GaHV-2 was propagated on cultured CEFs in T75 flasks by inoculating the original infected cell seed and incubating for seven days at $39^{\circ} \mathrm{C}$ with $5 \% \mathrm{CO}_{2}$. Only a very mild cytopathic effect was observed after this period. The harvested GaHV-2 stock solutions were kept in cryovials at $-80^{\circ} \mathrm{C}$ inside an isopropanol chamber overnight, and then stored in liquid nitrogen for further experimental use.

Cells were seeded at a density of $5.24 \times 10^{4}$ cells $/ \mathrm{mL}$ in 96 -well plates and allowed to rest at $39^{\circ} \mathrm{C}$ with $5 \%$ $\mathrm{CO}_{2}$ for $48 \mathrm{~h}$ before exposure. Treatment groups included: (i) infection with GaHV-2; (ii) exposure to perfluorooctane sulfonate (PFOS) (22 ppm-diluted in DMSO 1\%, Sigma, St Louis, USA), (iii) a combination of both (i.e. exposure to PFOS (22 ppm) followed by infection with GaHV-2, and (iv) non-exposure control group (media only). PFOS exposure always occurred at $48 \mathrm{~h}$, and GaHV-2 stimulation occurred at $72 \mathrm{~h}$. A ten-fold dilution of the GaHV-2 stock was used as the initial viral titer for well infections $(80 \mu \mathrm{l})$. Cells were harvested at $96 \mathrm{~h}$ post-seed, every $6 \mathrm{~h}$ for a $24-\mathrm{h}$ period (Additional file 1: Figure S1) via trypsinization: 2 PBS washes, addition of trypsin-EDTA $(50 \mu \mathrm{l})$ for 5 min at $39^{\circ} \mathrm{C}$, before resuspension in DMEM media and addition of $100 \mu \mathrm{l}$ lysis reagent (QIAzol $\left.{ }^{\circ}\right)$. Eight biological replicates were arranged per treatment and time point.

\section{RNA extraction, cDNA conversion and qPCR}

RNA was extracted using the miRNeasy Mini Kit (Qiagen, Oslo, Norway). The standard operating procedure from the manufacturer was used. Replicates from the same treatment and time point were pooled into new tubes to obtain sufficient amount of RNA for analysis, resulting in four treatments per time point. The extracted RNA was eluted into RNase-free water and stored overnight at $-20^{\circ} \mathrm{C}$. RNA concentration was determined using a NanoDrop ${ }^{\circ}$ ND-2000cUV-visible Spectrophotometer (NanoDrop Technologies, Wilmington, USA). Reverse transcription (RT) was performed on a fixed amount of RNA ( $50 \mathrm{ng} / \mu \mathrm{l}$ ) using the miScript II RT kit (Qiagen, Oslo, Norway) and quantitative (q) PCR was conducted using the miScript SYBR green PCR kit (Qiagen, Oslo, Norway). cDNAs were diluted to a final concentration of 1000 $\mathrm{pg} / \mu \mathrm{l}$ with nuclease free water and $6 \mathrm{ng}$ of the diluted cDNA was used in each $20 \mu \mathrm{l}$ qPCR reaction (run in technical duplicates). The mRNA assays included $10 \mu \mathrm{L}$ SYBR green and $2 \mu \mathrm{L}$ of each primer $(10 \mu \mathrm{M})$ (Additional file 2: Table S1) with the following running conditions: $15 \mathrm{~min}$ at $95^{\circ} \mathrm{C}$, three step cycling at $15 \mathrm{~s}$ at $94{ }^{\circ} \mathrm{C}, 30 \mathrm{~s}$ at $52^{\circ} \mathrm{C}$ and $45 \mathrm{~s}$ at $68^{\circ} \mathrm{C}$ for 50 cycles. After amplification and collection of fluorescence data, melt curve analysis was performed to exclude the possibility of non-specific amplification. Target genes represented a key transcription factor in immune signalling (NF-kB), a classical cytokine marker of inflammation (IL-8), a major pro-inflammatory chemokine (TNF- $\alpha$ ), a novel marker of inflammation (TNF- $\alpha$ ), and an anti-inflammatory cytokine (IL-4).

\section{Data analysis}

All analyses were performed in R (V 3.3.2) using the specialized package MCMC.qpcr [31]. Raw qPCR data (i.e. Ct values) were represented as molecule counts and described under a Poisson-lognormal error distribution using generalized linear mixed models. This approach is fully flexible for all levels of random and fixed effects, and it enables evaluation of unlimited interactions while increasing the power via simultaneous analysis of all genes in one model. Control genes are not required for this procedure [31] and thus were not implemented in this study. For analysis, a two-way design model was fitted using "treatment" (media only, PFOS only, GaHV-2 only, PFOS/GaHV-2) and "time point" (hours postinfection) as fixed factors (Eq. 1). The model has a single response variable, the natural logarithm of transcript counting rate. The most basic explanatory variable is 'gene' which accounts for different levels of expression between genes, the model is then augmented with the gene specific effects of our treatments ("gene:treatment") and time ("gene:timepoint"), and other random sources of variation (e.g. technical replicates) are also taken into account ("sample"). 


$$
\begin{aligned}
\operatorname{Ln}(\text { rate }) \sim \text { gene }+ \text { gene } & : \text { treatment }+ \text { gene } \\
& : \text { timepoint }+ \text { gene } \\
& : \text { timepoint } \\
& : \text { treatment }+ \text { sample }
\end{aligned}
$$

The Markov Chain Monte Carlo (MCMC) chain was run for 13,000 iterations (the first 3000 were discarded) to estimate the change in target mRNA in response to fixed effects. Results are presented as plots of inferred transcript $\log _{2}$ abundances (model estimates) arranged by gene, with \pm standard deviation (SD) of the estimate. Significant changes in expression were tested with MCMC-based $p$ values for each of the estimated parameters.

\section{Results}

Effect on basal immune gene expression - PFOS only A significant downregulation of NF-kB, IL-8 and IL-4 was found in primary chicken fibroblast cells exposed to PFOS. Following exposure to the pollutant, the basal expression (that is, media only) of the cytokines and transcription factor showed a consistent decrease across all time points (Fig. 1). Differences in relative gene expression were particularly remarkable at $42 \mathrm{~h}$ and $48 \mathrm{~h}$ post-exposure. Specifically, the basal expression of NF- $\mathrm{KB}$ was significantly lower than the control at $36 \mathrm{~h}$ and $42 \mathrm{~h}$ post-exposure $(36 \mathrm{~h}: p<0.001,42 \mathrm{~h}$ : $p=0.007,48 \mathrm{~h}: p<0.001)$. IL-8 expression decreased over time as well, with lower estimates from $36 \mathrm{~h}$ and a significant decrease at $48 \mathrm{~h}$ post-exposure $(p=0.021)$. A similar pattern applied to IL-4, with lower transcript levels at $48 \mathrm{~h}(p=0.004)$. Regarding TNF- $\alpha$, gene expression estimates in PFOS-exposed cells were similar or lower than in control cells, but no significant downregulation could be inferred.

\section{Infection of chicken embryo fibroblasts with GaHV-2}

The gene expression of the four immune genes (NF- $\kappa B$, IL-8, TNF- $\alpha$, IL-4) was determined in chicken embryo fibroblasts: 1) infected with GaHV-2 only and 2) media only control. When these two treatments were compared, they did not yield any statistically significant changes in their expression. This was consistent at all timepoints (i.e. between 6 and $24 \mathrm{~h}$ post-infection) (compared to media only; Fig. 2).

\section{Combined exposure and infection - PFOS/GaHV-2}

PFOS only exposed cells (which resulted in a significant decrease in immune gene expression) were next assessed in relation to PFOS/GaHV-2. In this scenario, the PFOS mediated depression of the immune genes was overridden and corrected to normal expression levels when infected with GaHV-2. Specifically, expression significantly increased in PFOS/GaHV-2 cells compared to PFOS only, for NF-kB $(p=0.002)$, IL-8 $(p=0.013)$ and IL-4 $(p<0.001)$ at $24 \mathrm{~h}$ post-infection. There was also a trend towards a higher expression of IL-8 after $18 \mathrm{~h}(p=0.077)$ (Fig. $3 \mathrm{~b})$. For TNF- $\alpha$, expression levels after $12 \mathrm{~h}$ were also significantly higher relative to PFOS only cells $(p=0.031)$. In addition, NF- $\mathrm{kB}$ expression at $6 \mathrm{~h}$ was upregulated relative to PFOS only ( $p=0.036)$ (Fig. 3a).

Exposure to PFOS/GaHV-2, compared to GaHV-2 only, did not yield statistically significant changes in the expression of the majority of the genes, however, there was significantly higher expression of NF- $\mathrm{kB}$ at $6 \mathrm{~h}$ postinfection $(p=0.042)$ (Fig. 2a).

\section{Discussion}

To investigate the potential of the most dominant PFAS in biota, i.e. PFOS, to modulate the innate immune response and disease resistance, this study utilised an in vitro model using CEFs. Prior to this study, there was no information available on the immunomodulatory properties of PFASs to avian innate immune responses and/or disease.

\section{PFOS modulation of basal immune gene expression}

This study provides the first empirical evidence that PFOS can modulate components of the avian innate immune system. These data shows that the expression of three immune genes in CEFs (i.e. NF- $\mathrm{kB}$, IL-8 and IL-4) were negatively modulated following exposure to PFOS. Changes in expression ranged between 3- and 5-fold decreases by $48 \mathrm{~h}$ post-exposure (Fig. 1).

Current knowledge about PFOS-mediated effects on innate immune signalling is limited and mostly based on mammalian models [5]. For example, PFOS attenuated the immune status of exposed mice, with a downregulation of basal hepatic levels of various cytokines, such as TNF- $\alpha$, IL-4 and IFN- $\gamma$ [5]. It has been suggested that PPAR $\alpha$ ligands, like PFASs, are anti-inflammatory, as receptor binding generally leads to a decrease in the activity of NF-kB and production of linked pro-inflammatory cytokines [13]. In addition, PPAR $\alpha$-independent pathways may partially account for PFOS immunotoxicity as well. For example, PFOS inhibits the degradation of inhibitor of kappa $B(I-k B)$ and the phosphorylation of the NF-kB protein p65 [33]. In line with this, the expression of two pro-inflammatory mediators (i.e. NF- $\mathrm{B}$ B and IL-8) were lowered by PFOS exposure in this current study, with TNF- $\alpha$ expression also lower, but not statistically significantly lower (Fig. 1). Regarding IL-4, a T helper cell type 2 (Th2) anti-inflammatory cytokine, previous studies have generally reported increased expression following PFOS exposure in rodents [34] and asthmatic humans [35]. This contrasts with the decrease of IL-4 expression in this current study (Fig. 1d), as well as in a study on murine hepatic macrophages [36]. Altogether, however, these 


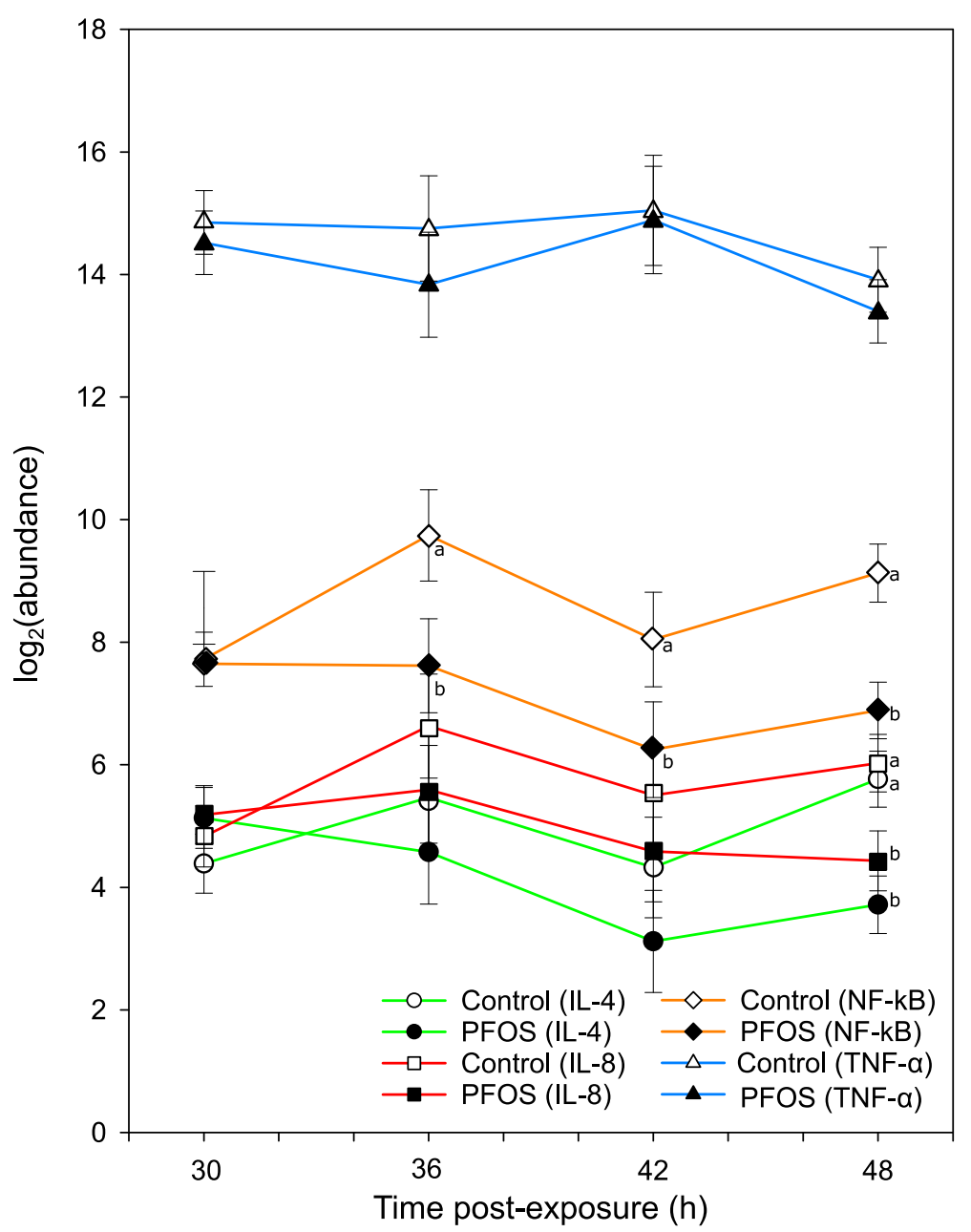

Fig. 1 Gene expression profile in response to PFOS only exposure. Overview of $\log _{2}$ (abundance) of gene transcripts (mRNA expression) in chicken embryo fibroblasts (CEFs) treated with PFOS (

$\triangle \triangle-$ ). The $\mathrm{x}$-axis denotes duration of the post-exposure period and the y-axis the model estimate for nuclear factor 'kappa-lightchain-enhancer' of activated B-cells (NF-KB), interleukin 8 (IL-8), tumor necrosis factor a (TNF-a) and interleukin 4 (IL-4). Model estimates are presented along with its SD in whiskers. Different letters indicate a significant pairwise difference for a given gene

findings suggest that PFOS can modulate the balance between Th1 and Th2 cytokines, towards humoral (Th2-like state) [30] or cellular (Th1-like state) immunity; importantly, either way, this represents a risk factor for disease development [35]. In conclusion, our findings in relation to PFOS exposure in avian cells are in agreement with the reported ability of PFASs to modulate cytokine production in mammalian immune cells $[20,37]$. This strengthens our knowledge of the potential of PFOS to interfere with activated immune signalling pathways and indicated a potential pathway of PFOS mediated adversity in avian species.

\section{Infection of chicken embryo fibroblasts with GaHV-2}

In this study, infection with GaHV-2 did not yield detectable changes in immune gene expression between 6 and $24 \mathrm{~h}$ post-infection for any of the investigated genes (Fig. 2). This was unexpected based on previous studies using the chicken and GaHV-2 model that reported increased levels of pro-inflammatory mediators, both in vivo $[29,30,38]$ and in vitro [32]. These responses probably took place within $24 \mathrm{~h}$ post-infection, and it is conceived that antiviral effects are linked to the early synthesis of pro-inflammatory cytokines in CEFs $[26,30]$. In vivo studies have shown that as early as $3-4$ days post-infection, if not earlier, various innate immune responses are detectable under normal circumstances (i.e. nitric oxide and pro-inflammatory cytokine release in various tissues) [30, 32]. However, in this current study, the inflammatory response following infection may have peaked later than measured (6-24h), likely due to infection at a lower initial viral titer in this study compared to that in previous studies. Further, during titration of the GaHV-2 only a slight cytopathic effect was 

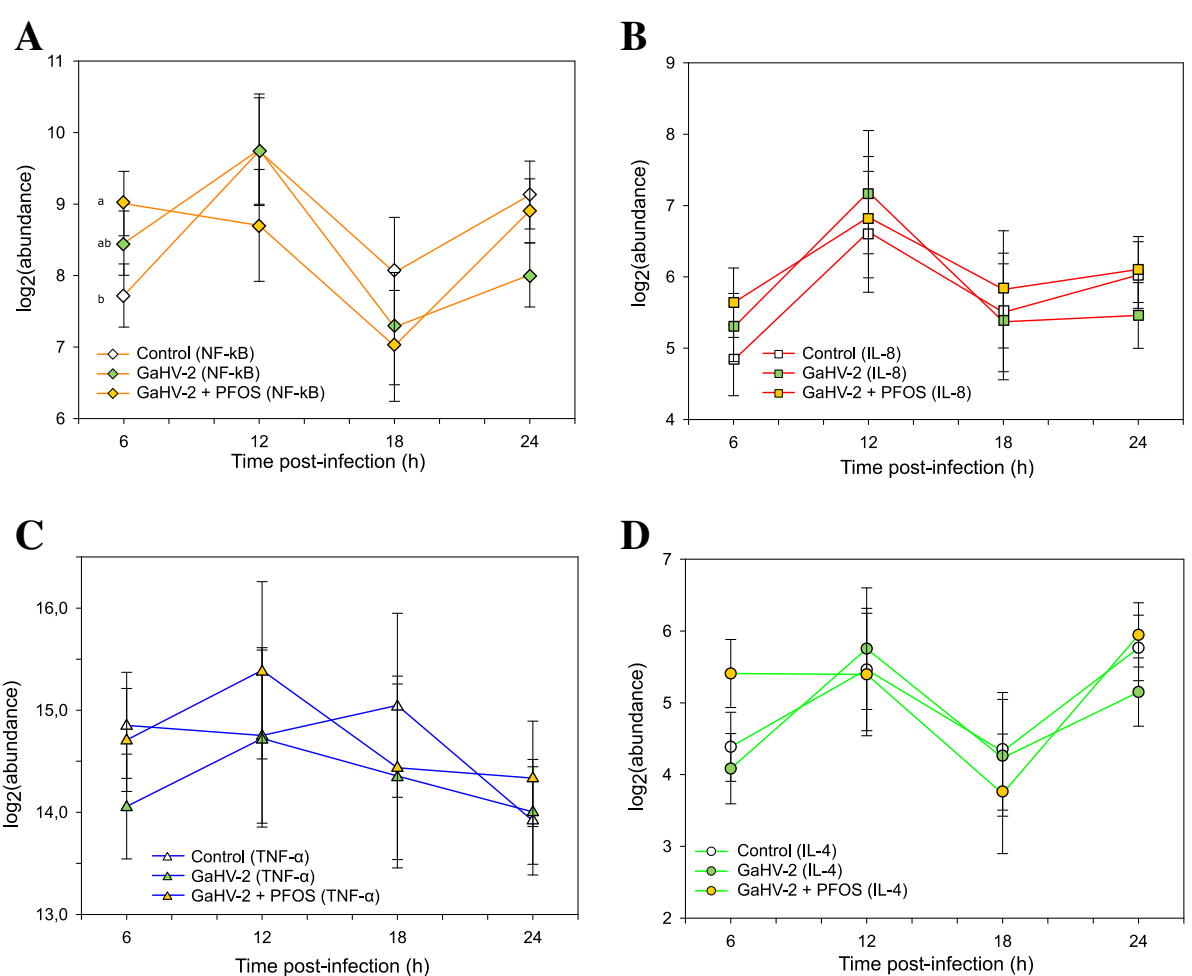

Fig. 2 Gene expression profile in response to GaHV-2 only and PFOS/GaHV-2 exposure. log2(abundance) of gene transcripts (mRNA expression) in chicken embryo fibroblasts (CEFs) infected with gallid herpesvirus-2 (GaHV-2) (

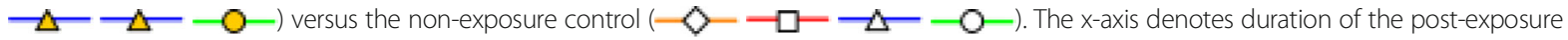
period and the $y$-axis the model estimate for nuclear factor 'kappa-light-chain-enhancer' of activated B-cells (NF-kB) (a), interleukin 8 (IL-8) (b), tumor necrosis factor a (TNF-a) (c) and interleukin 4 (IL-4) (d). Model estimates are presented along with its standard deviation in whiskers. Different letters indicate a significant pairwise difference for a given gene

noted after 7 days of infection. The exact viral titer could unfortunately not be quantified in this study, neither precisely compared to estimates of viral abundance used in similar infection studies: 100-1000 plaque-forming units (PFU) inoculated in vivo [30,38] or multiplicity of infection $(\mathrm{MOI})=0.001$ in CEF cultures [26]. IOther studies have, however, only detected later responses at the gene expression level (from $48 \mathrm{~h}$ ) in CEFs upon GaHV-2 infection, though shorter incubation times were not employed in these studies [17, 32]. Therefore, a mismatch between the harvesting time points and the peak response may, at least partially, account for the lack of detectable differences between control and GaHV-2 infected cells regarding pro-inflammatory genes. Higher viral titers and/or longer time points, compared to those used in the current study (Methods 2.1), might thus yield a more detectable response for these endpoints and should be further investigated in the future. In turn for IL4 , an anti-inflammatory cytokine, the fact that proinflammatory mediators were not upregulated to a significant extent might account for the lack of expression changes in this study. It has been shown that IL-4 release is negatively regulated during inflammation by proinflammatory mediators such as microRNA-155 [39, 40].

\section{Response of avian cells to combined exposures of PFOS and GaHV-2 infection}

While PFOS exposure had a negative effect on IL-8, NF$\kappa \mathrm{B}$ and IL-4 expression (Fig. 3), when the cells were exposed to PFOS/GaHV-2 the response returned to that of an 'unexposed' or 'healthy' host. This suggests that even though the immune gene expression in this study were below detection in virus exposed cells, the virus triggered a response that actually compensated for the negative effect of PFOS.

A possible explanation is that because the pollutant is known to alter cell membrane properties by increasing its permeability [42], the amount of infected cells in PFOS/GaHV-2 may have increased and increased proinflammatory gene expression back up to basal levels (Fig. 3). The upregulation of IL-4 in PFOS/GaHV-2 (Fig. 3d) may be explained by the synergistic production of damage associated molecular patterns (DAMPs), since PFOS exerts cell damage at sublethal concentrations 
A

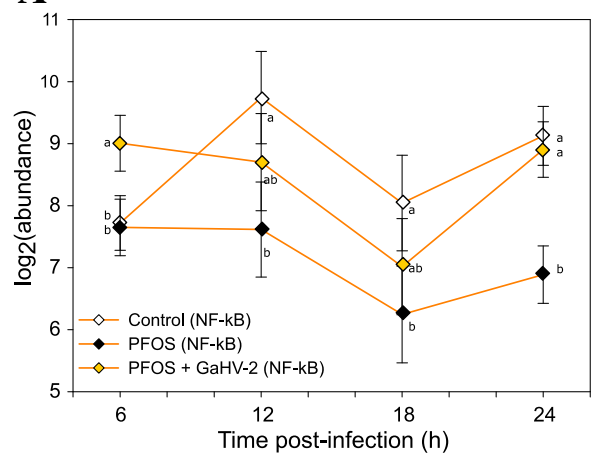

C

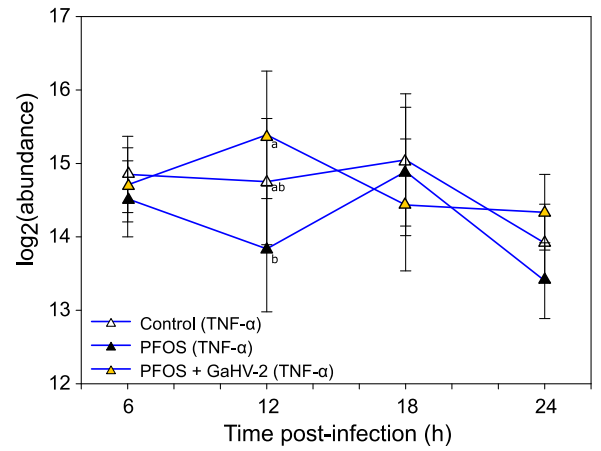

B

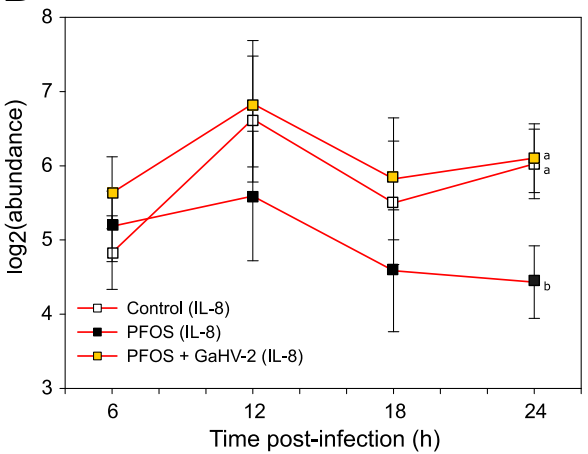

D

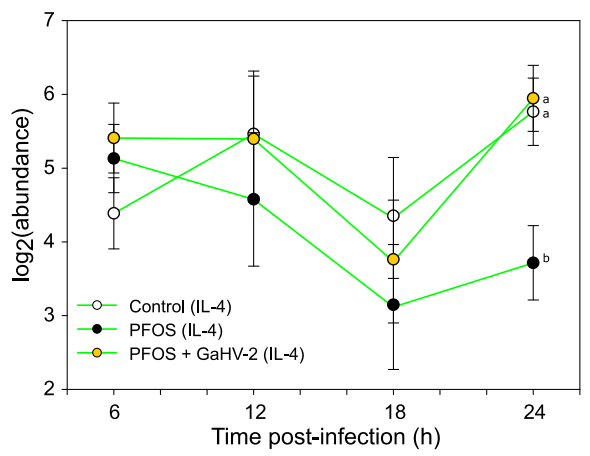

Fig. 3 Gene expression profile in response to PFOS only and PFOS/GaHV-2 exposure. log2(abundance) of gene transcripts (mRNA expression) in chicken embryo fibroblasts (CEFs) treated with PFOS ( $-\mathrm{O}-$ ), versus the non-exposure control ( the $\mathrm{y}$-axis the model estimate for nuclear factor 'kappa-light-chain-enhancer' of activated B-cells (NF-KB) (a), interleukin 8 (IL-8) (b), tumor necrosis factor a (TNF-a) (c) and interleukin 4 (IL-4) (d). Model estimates are presented along with its standard deviation in whiskers. Different letters indicate a significant pairwise difference for a given gene

that, in combination with infectious signals, may induce IL-4 as survival factor with antiapoptotic properties [43].

Alternatively, a protective effect of viruses on pollutant toxicity has previously been reported in birds [44]. In that study, mortality in mallard ducklings infected with duck hepatitis virus (DHV) and exposed to pesticides, namely DDT and dieldrin, was lower than in birds exposed to the pesticides only. It was suggested that the compensatory effect could relate to virus induced changes in pollutant metabolism, and this hypothesis was further supported by studies on the interaction of viruses with xenobiotic metabolism $[45,46]$. This exact mechanism is however unlikely to apply to this study, since GaHV-2 is not known to increase microsomal enzyme activity [47], PFOS has well-known stability [48] and fibroblasts have limited metabolic activity [49]. Nevertheless, this unexpected interaction between pollutant exposure and virus infections in birds remains an interesting area for further investigation.

Overall, no modulatory effects by PFOS on the response to GaHV-2 could be detected for these endpoints, as both treatments (GaHV-2 only and PFOS/GaHV-2) resembled the media only control (Fig. 2). However, induced inflammatory responses have been shown to be altered by exposure to PFOS in mammalian studies. For example, human leukocytes and mice splenocytes activated with lipopolysaccharide (LPS) had a lower release of TNF- $\alpha[20,41]$, whereas the inflammatory response to the same endotoxin was enhanced in mice macrophages [36]. These studies suggest that PFASs can affect NF- $\mathrm{KB}$ signalling and cytokine release through different mechanisms, as mentioned above [37], but this could unfortunately not be confirmed for GaHV-2 exposed avian cells in the current study, likely due to the mismatch between harvested timepoints and the immune response to infection.

\section{Conclusions}

To our knowledge, this is the first study to address changes in immune gene expression in response to PFOS in any bird host. The current study indicates that PFOS can interfere with key innate immune signalling pathway components in birds (NF-kB, IL-8, TNF- $\alpha$ and IL-4) (Fig. 1). Further, this study has unexpectedly 
provided evidence that PFOS mediated modulations can be mitigated via a virus infection.

Environmental contaminants have been overlooked as potential causative factors in infectious disease outcomes and severity [50,51], and future studies should keep the focus on innate functions, since they can impact resistance and they are traded off with other relevant physiological processes [15]. The interesting, seemingly positive (rather than the always assumed negative), interaction between PFOS and GaHV further highlights our lack of knowledge of these processes.

\section{Additional files}

Additional file 1: Figure S1. Timeline of pollutant exposure (PFOS) and viral infection with gallid herpesvirus-2 (GaHV-2) in the experiment. Treatment groups are shown in distinctively coloured arrows. In the table below, harvesting timepoints are given as both duration of the exposure period (hours post-exposure) or duration of the viral treatment (hours post-infection). (PDF $87 \mathrm{~kb}$ )

Additional file 2: Table S1. Primers used for mRNA qPCR analysis. Selected genes included the nuclear factor 'kappa-light-chain-enhancer' of activated B-cells (NF-KB1, interleukin 8 (IL-8), tumor necrosis factor alpha (TNF-a) and interleukin 4. Corresponding primer sequences were obtained from Sigma-Aldrich ${ }^{\oplus}[52,53]$. (DOCX 13 kb)

\section{Abbreviations}

cDNA: Complementary DNA; CEFs: Chicken embryo fibroblasts; Ct: Threshold cycle; DAMP: Damage associated molecular pattern; DHV: Duck hepatitis virus; DMSO: Dimethyl sulfoxide; FCS: Fetal calf serum; GaHV-2: Gallid herpesvirus-2; h: Hours; IFN: Inteferon; IL: Interleukin; I-kB: Inhibitor of kappa B; LPS: Lipopolysaccharide; MCMC: Markov chain monte carlo; MDV: Marek's disease virus; ml: Milliliters; mM: Millimolar; mRNA: Messenger ribonucleic acid; MyD88: Myeloid differentiation primary response 88; NF-kB: Nuclear factor 'kappa-light-chain-enhancer' of activated B-cells; ng: Nanograms; PAMP: Pathogen associated molecular pattern; PBS: Phosphate-buffered saline; PCR: Polymerase chain reaction; PFASs: Per- and polyfluoroalkyl substances; PFCAs: Perfluoroalkyl carboxylates; PFOA: Perfluorooctanoic acid; PFOS: Perfluorooctane sulfonate; PPARa: Peroxisome proliferator-activated receptor a; PRR: Pattern recognition receptor; qPCR: Quantitative polymerase chain reaction; RLR: Retinoic acid-inducible gene I-like receptor; RNA: Ribonucleic acid; RT: Reverse transcription; Th1: Helper T cells type 1; Th2: Helper T cells type 2; TLR: Toll-like receptor; TNF: Tumor necrosis factor

\section{Acknowledgements}

CW is supported by a postdoctoral fellowship (Fellow of Natural Sciences) from the Norwegian University of Science and Technology (NTNU). JCO acknowledges Alexander Badry for his support during the laboratory work.

\section{Authors' contributions \\ JCO: Contributed to the design of the study, conducted the analyses and data acquisition, analysed and interpreted the data, drafted the manuscript. VJ: contributed to the interpretation of data, critically and substantially revised the manuscript. CW: Conceived and designed the study, contributed to the analyses and data acquisition, analysed and interpreted the data, critically and substantially revised the manuscript. All authors read and approved the final manuscript}

\section{Funding}

CW is supported by a postdoctoral fellowship (Fellow of Natural Sciences) from the Norwegian University of Science and Technology (NTNU). The funding body provided monetary support only, and did not have any input into the design of the study, collection, analysis, and interpretation of data

\section{Availability of data and materials}

All data generated and analysed during this study are included in the published article (and its Supplementary file 1).

Ethics approval and consent to participate

Not applicable.

\section{Consent for publication}

Not applicable.

\section{Competing interests}

The author(s) declare(s) that they have no competing interests.

\section{Author details}

${ }^{1}$ Department of Biology, Norwegian University of Science and Technology (NTNU), Høgskoleringen 5, 7491 Trondheim, Norway. ${ }^{2}$ Present address: Catalan Institute for Water Research (ICRA), C/Emili Grahit 101, 17003 Girona, Spain.

Received: 21 January 2019 Accepted: 5 June 2019

Published online: 25 June 2019

\section{References}

1. Buck RC, Franklin J, Berger U, Conder JM, Cousins IT, De Voogt $P$, et al Perfluoroalkyl and polyfluoroalkyl substances in the environment: terminology, classification, and origins. Integr Environ Assess Manag. 2011; 7(4):513-41

2. Kissa E. Fluorinated surfactants and repellents. New York: Marcel Dekker, CRC Press; 2001

3. Lau C, Anitole K, Hodes C, Lai D, Pfahles-Hutchens A, Seed J. Perfluoroalkyl acids: a review of monitoring and toxicological findings. Toxicol Sci. 2007; 99(2):366-94.

4. Butt CM, Berger U, Bossi R, Tomy GT. Levels and trends of poly-and perfluorinated compounds in the arctic environment. Sci Total Environ. 2010;408(15):2936-65.

5. DeWitt JC, Peden-Adams MM, Keller JM, Germolec DR. Immunotoxicity of perfluorinated compounds: recent developments. Toxicol Pathol. 2012;40(2): 300-11.

6. Goudarzi H, Miyashita C, Okada E, Kashino I, Chen C-J, Ito S, et al. Prenatal exposure to perfluoroalkyl acids and prevalence of infectious diseases up to 4years of age. Environ Int. 2017;104:132-8.

7. Kannan K, Perrotta E, Thomas NJ. Association between perfluorinated compounds and pathological conditions in southern sea otters. Environ Sci Technol. 2006:40(16):4943-8.

8. Peden-Adams MM, Keller JM, EuDaly JG, Berger J, Gilkeson GS, Keil DE. Suppression of humoral immunity in mice following exposure to perfluorooctane sulfonate. Toxicol Sci. 2008;104(1):144-54.

9. Yang Q, Abedi-Valugerdi M, Xie Y, Zhao X-Y, Möller G, Nelson BD, et al. Potent suppression of the adaptive immune response in mice upon dietary exposure to the potent peroxisome proliferator, perfluorooctanoic acid. Int Immunopharmacol. 2002;2(2):389-97.

10. Peden-Adams MM, Stuckey JE, Gaworecki KM, Berger-Ritchie J, Bryant K, Jodice PG, et al. Developmental toxicity in white leghorn chickens following in ovo exposure to perfluorooctane sulfonate (PFOS). Reprod Toxicol. 2009; 27(3-4):307-18.

11. Smits JE, Nain S. Immunomodulation and hormonal disruption without compromised disease resistance in perfluorooctanoic acid (PFOA) exposed Japanese quail. Environ Pollut. 2013;179:13-8.

12. Sletten S, Bourgeon S, Bårdsen B-J, Herzke D, Criscuolo F, Massemin S, et al. Organohalogenated contaminants in white-tailed eagle (Haliaeetus albicilla) nestlings: an assessment of relationships to immunoglobulin levels, telomeres and oxidative stress. Sci Total Environ. 2016;539:337-49.

13. DeWitt JC, Shnyra A, Badr MZ, Loveless SE, Hoban D, Frame SR, et al. Immunotoxicity of Perfluorooctanoic acid and Perfluorooctane sulfonate and the role of peroxisome proliferator-activated receptor alpha. Crit Rev Toxicol. 2009;39(1):76-94

14. Juul-Madsen HR, Viertlboeck B, Smith AL, Göbel TW. Avian innate immune responses. Avian Immunol. 2008:129-58.

15. Martin LB, Hopkins WA, Mydlarz LD, Rohr JR. The effects of anthropogenic global changes on immune functions and disease resistance. Ann N Y Acad Sci. 2010;1195(1):129-48. 
16. Abdul-Careem MF, Haq K, Shanmuganathan S, Read LR, Schat KA, Heidari M, et al. Induction of innate host responses in the lungs of chickens following infection with a very virulent strain of Marek's disease virus. Virology. 2009; 393(2):250-7.

17. Li X, Su S, Cui N, Zhou H, Liu X, Cui Z. Transcriptome analysis of chicken embryo fibroblast cell infected with Marek's disease virus of GX0101 LTR. Revista Brasileira de Ciência Avícola. 2017;19(2):179-84.

18. Akira S, Sato S. Toll-like receptors and their signaling mechanisms. Scand J Infect Dis. 2003;35(9):555-62.

19. Cunard R, Ricote M, DiCampli D, Archer DC, Kahn DA, Glass CK, et al. Regulation of cytokine expression by ligands of peroxisome proliferator activated receptors. J Immunol. 2002;168(6):2795-802.

20. Corsini E, Avogadro A, Galbiati V, dell'Agli M, Marinovich M, Galli CL, et al. In vitro evaluation of the immunotoxic potential of perfluorinated compounds (PFCs). Toxicol Appl Pharmacol. 2011;250(2):108-16.

21. Stahl T, Mattern D, Brunn H. Toxicology of perfluorinated compounds. Environ Sci Eur. 2011;23(1):38

22. Osterrieder N, Kamil JP, Schumacher D, Tischer BK, Trapp S. Marek's disease virus: from miasma to model. Nat Rev Microbiol. 2006;4(4):283.

23. Baaten B, Staines K, Smith L, Skinner H, Davison T, Butter C. Early replication in pulmonary B cells after infection with Marek's disease herpesvirus by the respiratory route. Viral Immunol. 2009;22(6):431-44.

24. Van Hemert C, Pearce JM, Handel CM. Wildlife health in a rapidly changing north: focus on avian disease. Front Ecol Environ. 2014;12(10):548-56.

25. Jaspers VL. Selecting the right bird model in experimental studies on endocrine disrupting chemicals. Front Environ Sci. 2015;3:35.

26. Zou H, Su R, Ruan J, Shao H, Qian K, Ye J, et al. Toll-like receptor 3 pathway restricts Marek's disease virus infection. Oncotarget. 2017;8(41):70847.

27. Ma Y, He B. Recognition of herpes simplex viruses: toll-like receptors and beyond. J Mol Biol. 2014;426(6):1133-47.

28. Parvizi P, Abdul-Careem MF, Haq K, Thanthrige-Don N, Schat KA, Sharif S. Immune responses against Marek's disease virus. Anim Health Res Rev. 2010;11(2):123-34.

29. Jarosinski KW, Tischer BK, Trapp S, Osterrieder N. Marek's disease virus: lytic replication, oncogenesis and control. Expert Rev Vaccines. 2006;5(6):761-72.

30. Xing Z, Schat KA. Expression of cytokine genes in Marek's disease virusinfected chickens and chicken embryo fibroblast cultures. Immunology. 2000;100(1):70-6.

31. Matz MV, Wright RM, Scott JG. No control genes required: Bayesian analysis of qRT-PCR data. PLoS One. 2013;8(8):e71448.

32. Morgan RW, Sofer L, Anderson AS, Bernberg EL, Cui J, Burnside J. Induction of host gene expression following infection of chicken embryo fibroblasts with oncogenic Marek's disease virus. J Virol. 2001;75(1):533-9.

33. Corsini E, Luebke RW, Germolec DR, DeWitt JC. Perfluorinated compounds: emerging POPs with potential immunotoxicity. Toxicol Lett. 2014;230(2): 263-70.

34. Dong G-H, Liu M-M, Wang D, Zheng L, Liang Z-F, Jin Y-H. Sub-chronic effect of perfluorooctanesulfonate (PFOS) on the balance of type 1 and type 2 cytokine in adult C57BL6 mice. Arch Toxicol. 2011;85(10):1235-44.

35. Zhu Y, Qin X-D, Zeng X-W, Paul G, Morawska L, Su M-W, et al. Associations of serum perfluoroalkyl acid levels with T-helper cell-specific cytokines in children: by gender and asthma status. Sci Total Environ. 2016;559:166-73.

36. Qazi MR, Abedi MR, Nelson BD, DePierre JW, Abedi-Valugerdi M. Dietary exposure to perfluorooctanoate or perfluorooctane sulfonate induces hypertrophy in centrilobular hepatocytes and alters the hepatic immune status in mice. Int Immunopharmacol. 2010;10(11):1420-7.

37. Corsini E, Sangiovanni E, Avogadro A, Galbiati V, Viviani B, Marinovich M, et al. In vitro characterization of the immunotoxic potential of several perfluorinated compounds (PFCs). Toxicol Appl Pharmacol. 2012;258(2):248-55.

38. Katneni UK. Innate patterning of the immune response to Marek's disease virus (MDV) during pathogenesis and vaccination. PhD [dissertation] University of Delaware; 2015. Available from: University of Delaware Library, Museum and Press database.

39. Thai T-H, Calado DP, Casola S, Ansel KM, Xiao C, Xue Y, et al. Regulation of the germinal center response by microRNA-155. Science. 2007;316(5824): 604-8.

40. Rodriguez A, Vigorito E, Clare S, Warren MV, Couttet P, Soond DR, et al. Requirement of microRNA-155 for Normal immune function. Science. 2007; 316(5824):608-11.
41. Mollenhauer MA, Bradshaw SG, Fair PA, McGuinn WD, Peden-Adams MM. Effects of perfluorooctane sulfonate (PFOS) exposure on markers of inflammation in female B6C3F1 mice. J Environ Sci Health A. 2011;46(2):97-108,

42. Hu W, Jones PD, DeCoen W, King L, Fraker P, Newsted J, et al. Alterations in cell membrane properties caused by perfluorinated compounds. Comp Biochem Physiol C Toxicol Pharmacol. 2003;135(1):77-88.

43. Conticello C, Pedini F, Zeuner A, Patti M, Zerilli M, Stassi G, et al. IL-4 protects tumor cells from anti-CD95 and chemotherapeutic agents via upregulation of antiapoptotic proteins. J Immunol. 2004;172(9):5467-77.

44. Friend M, Trainer DO. Polychlorinated biphenyl: interaction with duck hepatitis virus. Science. 1970;170(3964):1314-6.

45. Kato R, Nakamura Y, Chiesara E. Enhanced phenobarbital induction of liver microsomal drug-metabolizing enzymes in mice infected with murine hepatitus virus. Biochem Pharmacol. 1963;12(4):365-70.

46. Buynitzky S, Ware $G$, Ragland W. Effect of viral infection on drug metabolism and pesticide disposition in ducks. Toxicol Appl Pharmacol. 1978;46(2):267-78.

47. Sakar D, Prukner-Radovčić E, Prevendar Crnić A, Pompe-Gotal J, Ragland W, Mazija H. Marek's disease vaccination, with Turkey herpesvirus, and enrofloxacin modulate the activities of hepatic microsomal enzymes in broiler chickens. Acta Vet Hung. 2004;52(2):211-7.

48. Olsen GW, Burris JM, Ehresman DJ, Froehlich JW, Seacat AM, Butenhoff JL, et al. Half-life of serum elimination of perfluorooctanesulfonate, perfluorohexanesulfonate, and perfluorooctanoate in retired fluorochemical production workers. Environ Health Perspect. 2007;115(9):1298.

49. Baron JM, Höller D, Schiffer R, Frankenberg S, Neis M, Merk HF, et al. Expression of multiple cytochrome P450 enzymes and multidrug resistanceassociated transport proteins in human skin keratinocytes. J Investig Dermatol. 2001;116(4):541-8.

50. Desforges J-P, Bandoro C, Shehata L, Sonne C, Dietz R, Puryear WB, et al. Environmental contaminant mixtures modulate in vitro influenza infection. Sci Total Environ. 2018;634:20-8.

51. Presley SM, Austin GP, Dabbert CB. Influence of pesticides and environmental contaminants on emerging diseases of wildlife. Wildlife toxicology: emerging contaminant and biodiversity issues. Boca Raton: CRC press; 2010. p. 74-109.

52. Ghareeb K, Awad WA, Soodoi C, Sasgary S, Strasser A, Böhm J. Effects of feed contaminant deoxynivalenol on plasma cytokines and mRNA expression of immune genes in the intestine of broiler chickens. PLoS One. 2013;8(8):e71492.

53. Annamalai T, Selvaraj RK. Interleukin 4 increases CCR9 expression and homing of lymphocytes to gut-associated lymphoid tissue in chickens. Vet Immunol Immunopathol. 2012;145(1):257-63.

\section{Publisher's Note}

Springer Nature remains neutral with regard to jurisdictional claims in published maps and institutional affiliations.

Ready to submit your research? Choose BMC and benefit from:

- fast, convenient online submission

- thorough peer review by experienced researchers in your field

- rapid publication on acceptance

- support for research data, including large and complex data types

- gold Open Access which fosters wider collaboration and increased citations

- maximum visibility for your research: over $100 \mathrm{M}$ website views per year

At $\mathrm{BMC}$, research is always in progress.

Learn more biomedcentral.com/submission 